\title{
Emergence of novel methicillin-resistant Staphylococcus aureus strains in a tertiary care facility in Riyadh, Saudi Arabia
}

This article was published in the following Dove Press journal: Infection and Drug Resistance

\author{
Abiola Senok (D) \\ Ali M Somily ${ }^{2}$ \\ Rania Nassar ${ }^{\prime}$ \\ Ghada Garaween ${ }^{3}$ \\ Garwin Kim Sing ${ }^{3}$ \\ Elke Müller ${ }^{4,5}$ \\ Annett Reissig ${ }^{4,5}$ \\ Darius Gawlik ${ }^{6}$ \\ Ralf Ehricht ${ }^{4,5}$ \\ Stefan Monecke ${ }^{4,5,7}$ \\ 'Department of Basic Medical Sciences, \\ College of Medicine, Mohammed Bin \\ Rashid University of Medicine and Health \\ Sciences, Dubai, United Arab Emirates; \\ ${ }^{2}$ Department of Pathology and \\ Laboratory Medicine, College of \\ Medicine, King Khalid University Hospital \\ and King Saud University, Riyadh, Saudi \\ Arabia; ${ }^{3}$ Department of Microbiology and \\ Immunology, College of Medicine, Alfaisal \\ University, Riyadh, Saudi Arabia; \\ ${ }^{4}$ InfectoGnostics Research Campus Jena, \\ Jena, Germany; ${ }^{5}$ Leibniz Institute of \\ Photonic Technology (IPHT), Jena, \\ Germany; ${ }^{6}$ PTC - Phage Technology \\ Center $\mathrm{GmbH}$, Bönen, Germany; \\ ${ }^{7}$ Medical Faculty "Carl Gustav Carus", \\ Institute for Medical Microbiology and \\ Hygiene, Technische Universität Dresden, \\ Dresden, Germany
}

Correspondence: Abiola Senok College of Medicine, Mohammed Bin Rashid University of Medicine and Health Sciences, P.O. Box 505055, Dubai, United Arab Emirates

Tel +97I $438387 / 7$

Email abiola.senok@mbru.ac.ae
Purpose: There is a need for continuous surveillance of methicillin-resistant Staphylococcus aureus (MRSA) to identify emergence of new strains. We hypothesize that MRSA strains are evolving with ongoing acquisition of SCCmec elements. This study was carried out to evaluate the evolution of MRSA at a tertiary care facility in Saudi Arabia.

Methods: MRSA isolates associated with invasive clinical infection, which were identified in 2017 at the microbiology laboratory, King Khalid University Hospital (KKUH) in Riyadh, Saudi Arabia, were studied. The molecular characterization of isolates was carried out using StaphyType DNA microarray (Alere Technologies GmbH/Abbott, Jena, Germany).

Results: The 125 MRSA isolates studied belonged to 18 clonal complexes (CC) which were distributed into 32 strain assignments. The predominant CC were CC5 (n=30), CC6 $(n=17)$, CC80 ( $n=13), \operatorname{CC} 22(n=12), \operatorname{CC} 361(n=12)$. The findings demonstrated the first identification of CC152, CC361 and CC1153 MRSA as well as ST5-MRSA-[I+fus], "Geraldine Clone", CC6-MRSA-IV (PVL+) and CC88-MRSA-V (PVL+), WA MRSA-117 in Saudi Arabia. Four novel variants were identified: CC5-MRSA-[VI+fus+tirS], CC22-MRSA-[V/VT+fus] (PVL+), CC152-MRSA-[V+fus](PVL+) and CC361-MRSA-[VT+fus]. Fifty-four isolates (n/ $\mathrm{N}=54 / 125 ; 43.2 \%$ ) including the novel strains carried the Q6GD50 SCCfusC gene while the Panton-Valentine leukocidin genes were present in $30.4 \%(\mathrm{n} / \mathrm{N}=38 / 125)$.

Conclusion: The findings demonstrate an expanding MRSA repertoire in our setting including emergence of previously unreported clonal complexes and novel strains. The high carriage of fusC gene suggests a role for fusidic acid misuse in driving the evolution of the MRSA genome and underscores the need for increased monitoring of antibiotic use. Keywords: DNA microarray, fusidic acid, clonal complex, panton-valentine leukocidin

\section{Introduction}

Methicillin-resistant $S$. aureus (MRSA) which was first described in the 1960 s remains a major etiological agent of community-acquired and nosocomial infections. MRSA infections contribute to the burden of health care accounting for significant morbidity, mortality with significant economic consequences. ${ }^{1}$ The epidemiology of MRSA is dynamic and ever evolving with community-acquired MRSA lineages (CA-MRSA) being identified as increasingly relevant also in the health care sector. ${ }^{2,3}$

Antibiotic resistance in MRSA is mediated by the presence of modified penicillinbinding protein (PBP2a), which is encoded for by alleles of the mecA gene located on SCCmec (staphylococcal cassette chromosome mec) element. In addition to the mecA 
gene, this large, genetic element also harbors regulatory genes, recombinase genes and a variety of accessory genes. The nomenclature of the SCCmec elements is based on the composition of the regulatory and recombinase genes as well as those of additional genes within the mec complex which encode for other resistance mechanisms or virulence determinants. ${ }^{2,4}$ Pseudo-SCCmec elements which are truncated with absence of the $c c r$ recombinase genes as well as SCC elements lacking mec genes but harboring other markers such as the fusidic acid resistance gene fus $C$ have been described in the literature. ${ }^{5,6}$ High-resolution typing utilizing newly developed probes been used to differentiate SCCmec types into various subtypes. ${ }^{3,6}$

In Saudi Arabia, MRSA infections contribute significantly to the burden of health care delivery with increasing occurrence of CA-MRSA lineages causing nosocomial infections. ${ }^{7,8}$ Recently reported work showed the presence of a high degree of diversity and an emergence of both pandemic and rare MRSA strains among isolates obtained from 2009 to 2015 at King Khaled University Hospital (KKUH), Riyadh, Saudi Arabia. ${ }^{8}$ Further work also showed that MRSA colonizing health care workers at the facility were of similar population structure as those identified in patients. ${ }^{9}$

The changing epidemiology of MRSA necessitates the continuous surveillance particularly in Saudi Arabia and the Arabian Gulf region where a dynamic population movement exists. The large expatriate population, increasing numbers of tourists and, specifically in Saudi Arabia, the annual influx of millions of Hajj pilgrims makes it plausible that the Arabian Gulf region might be pivotal in the global transmission of MRSA clones. This need for surveillance is underscored by the recent report of the diversity of CC22MRSA-IV strains across the Arabian Gulf region. ${ }^{3}$ Using high-resolution typing, at least six CC22MRSA-IV strains differing in SCCmec subtypes and toxin carriage were identified from three countries in the region. ${ }^{3}$ We speculate that new MRSA strains might continuously evolve in our health care facilities and the acquisition of SCCmec elements might occur more commonly than appreciated. The present study was carried out to evaluate the evolution of MRSA at a tertiary care center in the capital of Saudi Arabia, Riyadh, and findings demonstrate the emergence of novel variants and previously unidentified MRSA strains.

\section{Materials and methods}

\section{Specimen collection and bacterial strains}

The study was carried out at the King Khalid University Hospital (KKUH) in Riyadh, Saudi Arabia. Ethical approval was obtained from the hospital ethics committee. MRSA isolates associated with invasive clinical infection identified in 2017 were studied. Bacterial identification, confirmation of methicillin resistance and antibiotic susceptibility testing were performed in accordance with Clinical and Laboratory Standards Institute guidelines as previously described. ${ }^{8}$

\section{DNA microarray for molecular characterization}

All isolates were characterized using microarray assays for $S$. aureus typing and characterization of SCC elements (Alere Technologies GmbH/Abbott, Jena, Germany). The probes, primers and procedures used in the assay for detection of species markers, virulence genes, resistance genes and SCCmec subtyping have been described previously. ${ }^{6,10}$ Assays were carried out in accordance with manufacturer provided protocols. The analysis of presence or absence of target gene, strain and clonal complex assignment and SCCmec subtype was carried out as previously described. ${ }^{6,10}$

\section{Results}

A total of 125 MRSA isolates associated with clinical infections obtained in 2017 at KKUH microbiology laboratory were studied. The isolates were obtained from blood $(n=25)$, respiratory aspirates $(n=20)$ and wound swabs $(n=80)$. Based on DNA microarray analysis, these 125 MRSA isolates were grouped into 18 clonal complexes (CC) which were distributed into 32 strain assignments based on $\mathrm{CC}$ affiliation, toxin gene carriage and SCCmec subtype (Table 1). The predominant $\mathrm{CC}$ were $\operatorname{CC5}(\mathrm{n}=30), \operatorname{CC} 6(\mathrm{n}=17), \operatorname{CC} 80(\mathrm{n}=13), \operatorname{CC} 22$ ( $\mathrm{n}=12), \operatorname{CC} 361$ $(\mathrm{n}=12)$ (Table 1). The findings demonstrated the first identification of CC152, CC361 and CC1153 MRSA in Saudi Arabia. Furthermore, we report the first identification of ST5-MRSA-[I +fus], "Geraldine Clone", CC6-MRSA-IV (PVL+) and CC88MRSA-V (PVL+), WA MRSA-117 in Saudi Arabia (Table 1). Three isolates identified as MRSA phenotypically were genotypically characterized as CC2250 S. argenteus.

Four novel variant of MRSA strains were identified. These strains belong to CC5, CC22, CC152 and CC361. Table 2 shows the molecular characterization of these four MRSA strains. Except for the CC5 strain with $\mathrm{SCCmecVI}$, all others harbored SCCmec V. Almost half of the total isolates $(\mathrm{n} / \mathrm{N}=54$ / $125 ; 43.2 \%$ ) including all the novel strains carried the 
Table I Distribution of clonal complex and strain affiliations

\begin{tabular}{|c|c|c|c|}
\hline Clonal complex (CC) & Strain affiliations & \# of isolates & Novel variants \\
\hline $\mathrm{CCl}(\mathrm{n}=8)$ & CCI-MRSA-[IV+fus+ccrABI], WA MRSA-I/45 & 8 & \\
\hline $\operatorname{CC5}(n=30)$ & $\begin{array}{l}\text { CC5-MRSA-IV (PVL+/edinA+), WA MRSA-I2I } \\
\text { CC5-MRSA-[IV+fus+ccrAB], Maltese Clone } \\
\text { CC5-MRSA-IV (tstl+), Paediatric clone } \\
\text { ST5-MRSA-[l+fus], Geraldine Clone } \\
\text { CC5-MRSA-[V/VT+fus] } \\
\text { CC5-MRSA-[VI+fus] }\end{array}$ & $\begin{array}{l}5 \\
4 \\
1 \\
1 \\
12 \\
7\end{array}$ & 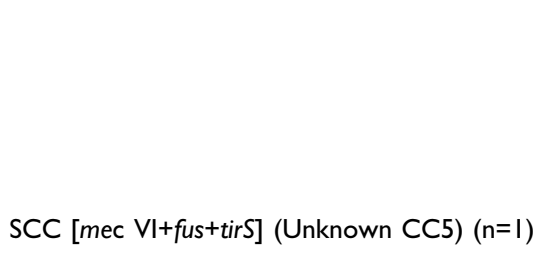 \\
\hline $\operatorname{CC6}(n=17)$ & $\begin{array}{l}\text { CC6-MRSA-IV, WA MRSA-5I } \\
\text { CC6-MRSA-IV (PVL+) }\end{array}$ & $\begin{array}{l}15 \\
2\end{array}$ & \\
\hline CC8 $(n=1)$ & ST8-MRSA-[IV+ACME] (PVL+), USA300 & 1 & \\
\hline $\operatorname{CCI} 5(n=1)$ & CCI5-MRSA-[V+fus] & 1 & \\
\hline CC22 $(n=12)$ & $\begin{array}{l}\text { CC22-MRSA-IV (tstl+), “Gaza Epidemic Strain” } \\
\text { CC22-MRSA-IV (PVL+) } \\
\text { CC22-MRSA-IV (PVL+/tst+) } \\
\text { CC22-MRSA-[V/VT+fus] (PVL+) }\end{array}$ & $\begin{array}{l}5 \\
1 \\
5 \\
1\end{array}$ & SCCmec V/VT+fus (Unknown CC22) \\
\hline CC30 $(n=3)$ & $\begin{array}{l}\text { CC30-MRSA-[VI+fus] (PVL+/tstl) } \\
\text { CC30-MRSA-IV (PVL+), Southwest Pacific Clone }\end{array}$ & $\begin{array}{l}1 \\
2\end{array}$ & \\
\hline CC45 $(n=1)$ & CC45-MRSA-IV, WA MRSA-23 & I & \\
\hline CC72 $(n=2)$ & ST72-MRSA-IV, USA700 & 2 & \\
\hline $\operatorname{CC} 80(n=13)$ & CC80-MRSA-IV (PVL+) & 13 & \\
\hline CC88 $(n=7)$ & $\begin{array}{l}\text { CC88-MRSA-IV (PVL+) } \\
\text { CC88-MRSA-[IV+fus] } \\
\text { CC88-MRSA-V (PVL+), WA MRSA-II7 }\end{array}$ & $\begin{array}{l}3 \\
3 \\
1\end{array}$ & \\
\hline $\operatorname{CC96}(n=5)$ & CC96-MRSA-IV & 5 & \\
\hline $\operatorname{CC97}(n=6)$ & CC97-MRSA-[V/VT+fus] & 6 & \\
\hline $\operatorname{CCI} 52(n=1)$ & CCI52-MRSA-[V+fus] (PVL+) & I & $\mathrm{SCC}[\mathrm{mec} \mathrm{V}+$ fus] (Unknown CCI52) \\
\hline CC239 $(n=2)$ & CC239-MRSA-[III+ccrC] & 2 & \\
\hline $\operatorname{CC} 36 \mid(n=\mid 2)$ & $\begin{array}{l}\text { CC36I-MRSA-[V/VT] } \\
\text { CC36I-MRSA-V/VT (PVL+) } \\
\text { CC36I-MRSA-[V/VT+fus] }\end{array}$ & $\begin{array}{l}3 \\
1 \\
8\end{array}$ & SCC [mec VT+fus] (Unknown CC36I) \\
\hline $\operatorname{CCII} 53(n=1)$ & CCII53-MRSA-[V/VT+fus] (PVL+) & 1 & \\
\hline $\operatorname{CC} 2250(n=3)$ & CC2250-MRSA-IV, WA MRSA-II4 & 3 & \\
\hline
\end{tabular}

Q6GD50 (fusC, SCC-borne fusidic acid resistance) (Table 2). None of the isolates harbored the vancomycin or mupirocin resistance genes. Table 3 shows the distribution of carriage of virulence and antibiotic resistance genes among all 125 isolates. The Panton-Valentine leukocidin $(p v l)$ genes were found in $30.4 \%(\mathrm{n} / \mathrm{N}=38 / 125)$ of isolates. The predominant virulence genes identified were sak and scn which were present in $96 \%$ of isolates.

\section{Discussion}

The identification of MRSA strains which have not been previously reported from Saudi Arabia and novel variants of MRSA strains demonstrate the continuing evolution of MRSA in our setting. Over $40 \%$ of the MRSA isolates identified harbored the fusidic acid resistance gene fusC presumably as additional payload on the SCCmec genetic element. A similar high occurrence of co-carriage of $f u s C$ 
Table 2 Characterization of novel variants of methicillin-resistant Staphylococcus aureus strains

\begin{tabular}{|c|c|c|c|c|c|c|}
\hline $\begin{array}{l}\text { Found in } \\
\text { clonal } \\
\text { complex }\end{array}$ & $\begin{array}{l}\text { Novel MRSA } \\
\text { variants }\end{array}$ & $\begin{array}{l}\text { SCC mec-complex- } \\
\text { associated genes }\end{array}$ & $\begin{array}{l}\text { Regulatory } \\
\text { gene }\end{array}$ & $\begin{array}{l}\text { Capsule } \\
\text { gene }\end{array}$ & $\begin{array}{l}\text { Antibiotic } \\
\text { resistance genes }\end{array}$ & Virulence genes \\
\hline CC5 & $\begin{array}{l}\text { CC5-MRSA- } \\
{[\mathrm{VI}+\text { fust tirS }]}\end{array}$ & $\begin{array}{l}\text { mecA; mecRI; ugpQ; ccrA-4; } \\
\text { ccrB-4; Q6GD50 (fusC);tirS }\end{array}$ & agrll & cap5 & $\begin{array}{l}\text { blaZ; blal; blaR; dfrA; } \\
\text { tetM; fexA; fosB; } \\
\text { tetEfflux }\end{array}$ & $\begin{array}{l}\text { entD/G/IIJ/M/N/R/U; sak; } \\
\text { scn }\end{array}$ \\
\hline $\mathrm{CC} 22$ & $\begin{array}{l}\text { CC22-MRSA- } \\
{[\mathrm{V} / \mathrm{VT}+\text { fus }]} \\
\left(\mathrm{PVL}^{+}\right)\end{array}$ & $\begin{array}{l}\text { mecA, ugpQ; ccrAA; ccrC; } \\
\text { Q6GD50 (fusC) }\end{array}$ & agrB-IV & cap5 & $\begin{array}{l}\text { blaZ; blal; blaR; aacA- } \\
\text { aphD; dfrA; tetK }\end{array}$ & $\begin{array}{l}\text { tstl; entC/G/I/L/M/N/O/U; } \\
\text { lukF/S-PVL; sak; chp; scn; } \\
\text { fnbB }\end{array}$ \\
\hline $\mathrm{CCI} 52$ & $\begin{array}{l}\text { CCI52-MRSA- } \\
{[\mathrm{V}+\text { fus }]\left(\mathrm{PVL}^{+}\right)}\end{array}$ & $\begin{array}{l}\text { mecA, ugpQ; Q6GD50 } \\
\text { (fusC); сcrAA; ccrC }\end{array}$ & agrl; agrB-IV & cap5 & $\begin{array}{l}\text { aacA-aphD; tetK; } \\
\text { tetEfflux }\end{array}$ & $\begin{array}{l}\text { lukF/S-PVL; sak; scn; fnbA; } \\
\text { fnbB; ica A/D }\end{array}$ \\
\hline CC36I & $\begin{array}{l}\text { CC36I-MRSA- } \\
{[\mathrm{VT}+\text { fus }]}\end{array}$ & $\begin{array}{l}\text { mecA; ugpQ; ccrAA; ccrC; } \\
\text { Q6GD50 (fusC) }\end{array}$ & agrl; agrB-IV & cap8 & $\begin{array}{l}\text { blaZ; blal; blaR;msrA; } \\
\text { aphA3; sat;fosB; } \\
\text { tetEfflux }\end{array}$ & $\begin{array}{l}\text { entG/I/M/N/O/U; sak; scn; } \\
\text { fnbA; fnbB }\end{array}$ \\
\hline
\end{tabular}

and SCCmec elements has been shown in MRSA isolates from Kuwait. ${ }^{5}$ It is of interest that all the novel variants identified harbored the SCCmec/fusC element. This evolution of SCCmec/fusC composite element is probably due to a survival benefit for the strains driven in part by misuse of fusidic acid given its availability in our setting as an over-the-counter medication in the community. The presence of composite SCCmec/fusC element and chimeras of multiple progenitor cassettes has been demonstrated in fusidic-acid-resistant MRSA strains in the United Kingdom. ${ }^{11}$ It was suggested that the occurrence of strains harboring genetic elements which include SCCmec, antibiotic resistance and virulence genes may be indicative of novel adaptive mechanisms in MRSA. ${ }^{11}$ Indeed, this adaptive mechanism could drive the emergence of new MRSA strains such of the novel variants of MRSA strains shown in this study.

CC5-MRSA is a common clonal complex which encompasses a large variety of MRSA strains. ${ }^{10}$ CC5-MRSA is prevalent in the Arabian Gulf region with CC5-MRSA-IV (PVL+/edinA+), WA MRSA-121, CC5-MRSA-[IV+fus $+\operatorname{ccr} A B]$, "Maltese Clone" and CC5-MRSA-IV (tst1+), "Pediatric clone" previously identified from Saudi Arabia (including from KKUH), Kuwait and Qatar. 5,8,12,13 Although CC5-MRSA-V has been identified in the UAE and Saudi Arabia, the CC5-MRSA-[V/VT+fus] reported in this study had only been described from Kuwait. ${ }^{5,8,13}$ Our findings demonstrate the emergence of CC5-MRSA-VI in the Arabian Gulf region. CC5-MRSA-VI was first described in Portugal and has been reported in France, Colombia, Argentina and the USA while the PVL-positive CC5-
MRSA-VI has been reported from Switzerland. ${ }^{10,14-16}$ All the CC5-MRSA-VI identified in this study harbored the SCCmec/fusC genetic element. In addition, we describe a novel variant with $\mathrm{SCC}[$ mec $\mathrm{VI}+f u s+t i r S]$ harboring the Staphylococcal TIR-protein-binding protein (tirS) as additional payload. The presence of the tirS gene in $S$. aureus has been associated with enhanced bacterial survival in the host as well as increased virulence through attenuation of the TLR2 immune response. ${ }^{17}$ The horizontal transfer of this gene among MRSA isolates circulating in our setting is probable as it is localized on a mobile genetic element. This scenario might drive the evolution of MRSA toward emergence of strains with increased bacterial fitness and virulence.

A single isolate of the ST5-MRSA-[I+fus] "Geraldine Clone" was identified and to the best of our knowledge, this is the first description of this strain in the Arabian Gulf region. The ST5-MRSA-[I+fus] "Geraldine Clone" was first described in 2003 in France where it is a prevalent clone associated with outbreaks, particularly in the neonatal setting. ${ }^{18,19}$ In 2012, a single ST5-MRSA-[I+fus] "Geraldine Clone" was reported in Saxony, Germany, in a patient with a history of foreign travel. ${ }^{6}$ A travel link could also explain the emergence of this strain in our setting. Although verification of a travel history in this instance was not possible due to lack of access to patient data, the large expatriate population and common occurrences of travel for medical reasons in our setting makes this highly plausible.

CC152-MRSA-V has been reported from Germany, Australia, Sweden, Switzerland and Kuwait. ${ }^{5,10}$ In keeping 
Table 3 Distribution of virulence and resistance gene markers

\begin{tabular}{|c|c|c|c|}
\hline \multicolumn{2}{|l|}{ Virulence and resistance gene markers } & \multirow{2}{*}{$\begin{array}{l}\text { Number of positive isolates } \\
(\mathbf{N}=125)\end{array}$} & \multirow{2}{*}{$\begin{array}{l}\begin{array}{l}\text { Percentage of positive } \\
\text { isolates }\end{array} \\
42.4\end{array}$} \\
\hline Accessory gene regulator allele I & agrl & & \\
\hline Accessory gene regulator allele II & agrll & 32 & 25.6 \\
\hline Accessory gene regulator allele III & agrIII & 36 & 28.8 \\
\hline Accessory gene regulator allele IV & agrlV & 7 & 5.6 \\
\hline Alternate penicillin-binding protein 2 , defining MRSA & mecA & 125 & 100 \\
\hline \multirow[t]{2}{*}{ Mercury resistance operon } & merA & 0 & 0 \\
\hline & merB & 0 & 0 \\
\hline \multirow[t]{2}{*}{ Sccmec XI } & $\operatorname{mec} C$ & 0 & 0 \\
\hline & $\begin{array}{l}\text { blaZ- } \\
\text { SCCmec XI }\end{array}$ & 0 & 0 \\
\hline Beta-lactamase & blaZ & 115 & 92 \\
\hline Beta lactamase repressor (inhibitor) & blal & 115 & 92 \\
\hline Beta-lactamase regulatory protein & blaR & 114 & 91.2 \\
\hline $\begin{array}{l}\text { Rrna adenine N-6-methyl-transferase, erythromycin/ } \\
\text { clindamycin resistance }\end{array}$ & ermA & 4 & 3.2 \\
\hline Erythromycin/clindamycin resistance & ermB & 0 & 0 \\
\hline Erythromycin/clindamycin resistance & erm C & 36 & 28.8 \\
\hline Lincosamide nucleotidyltransferase & $\operatorname{lin} A$ & 1 & 0.8 \\
\hline Energy-dependent efflux of erythromycin & msrA & 13 & 10.4 \\
\hline Bifunctional enzyme Aac/Aph, gentamicin resistance & aacA-aphD & 22 & 17.6 \\
\hline Amino-glycoside adenyl-transferase,tobramycin resistance & $\operatorname{aadD}$ & 7 & 5.6 \\
\hline $\begin{array}{l}\text { 3'5'-aminoglycoside phospho-transferase, neo-/ kanamycin } \\
\text { resistance }\end{array}$ & aphA3 & 23 & 18.4 \\
\hline Streptothricine-acetyl-transferase & sat & 23 & 18.4 \\
\hline Dihydrofolate reductase type I & dfrA & 18 & 14.4 \\
\hline Fusidic acid resistance & farl & 13 & 10.4 \\
\hline Hypothetical protein associated with fusidic acid resistance & $\begin{array}{l}\text { Q6GD50 } \\
\text { (fusC) }\end{array}$ & 54 & 43.2 \\
\hline Mupirocin resistance protein & mupR & 0 & 0 \\
\hline Tetrazyklin resistance & tetK & 22 & 17.6 \\
\hline Tetracycline resistance & tetM & 9 & 7.2 \\
\hline Chloramphenicol acetyltransferase & cat & 0 & 0 \\
\hline 23S Rrna methyltransferase & $c f r$ & 0 & 0 \\
\hline Chloramphenicol/florfenicol exporter & fexA & 7 & 5.6 \\
\hline
\end{tabular}


Table 3 (Continued).

\begin{tabular}{|c|c|c|c|}
\hline \multicolumn{2}{|l|}{ Virulence and resistance gene markers } & \multirow{2}{*}{$\begin{array}{l}\text { Number of positive isolates } \\
(\mathrm{N}=\mid 25)\end{array}$} & \multirow{2}{*}{$\begin{array}{l}\text { Percentage of positive } \\
\text { isolates }\end{array}$} \\
\hline Metallothiol transferase & fos $B$ & & \\
\hline & fosB-plasmid & 0 & 0 \\
\hline Quaternary ammonium compound resistance protein A & qacA & 2 & 1.6 \\
\hline Quaternary ammonium compound resistance protein C & qacC & 0 & 0 \\
\hline Transport/effluxprotein & tetEfflux & 110 & 88 \\
\hline Vancomycin resistance gene & $\operatorname{van} A$ & 0 & 0 \\
\hline Vancomycin resistance gene from enterococci and Clostridium & $\operatorname{van} B$ & 0 & 0 \\
\hline Teicoplanin resistance gene from enterococci & $\operatorname{vanZ}$ & 0 & 0 \\
\hline Toxic shock syndrome toxin I & $\begin{array}{l}\text { tst I } \\
\text { (consensus) }\end{array}$ & 14 & 11.2 \\
\hline Panton Valentine leukocidin F component & lukF-PV & 38 & 30.4 \\
\hline Panton Valentine leukocidin S component & lukS-PV & 38 & 30.4 \\
\hline Staphylokinase & sak & 120 & 96 \\
\hline Chemotaxis-inhibiting protein & chp & 38 & 30.4 \\
\hline Staphylocccal. Complement inhibitor & sen & 121 & 96.8 \\
\hline Exfoliative toxin serotype $A$ & et $A$ & 0 & 0 \\
\hline Exfoliative toxin serotype $B$ & etB & 0 & 0 \\
\hline Exfoliative toxin $D$ & et $D$ & 13 & 10.4 \\
\hline Epidermal cell differentiation inhibitor & edinA & 5 & 4 \\
\hline Epidermal cell differentiation inhibitor B & edinB & 14 & 11.2 \\
\hline Epidermal cell differentiation inhibitor $C$ & edinC & 0 & 0 \\
\hline Arginine catabolic mobile element locus & ACME & I & 0.8 \\
\hline
\end{tabular}

with reported literature on CC152-MRSA-V, our isolate harbored the $p v l$ and $e \operatorname{din} B$ genes, and lacked enterotoxin genes. ${ }^{10}$ The CC152-MRSA-[V+fus] $(\mathrm{PVL}+)$ identified in this study is very similar to that recently reported as a novel variant with the carriage of the SCCfusC element. However, our isolate had the fibronectin-binding protein genes $(f n b A$, $f n b B)$ which was not present in the previously described isolates. $^{5}$

The findings in this study demonstrate the first identification of CC361 strains in Saudi Arabia. CC361-MRSA-V has been described in the UAE and recently CC361-MRSA-[V/VT+fus] was reported in Kuwait. ${ }^{5,10}$ The CC361-MRSA-[V/VT+fus] harboring the SCCmec $\mathrm{VT}+$ fus genetic element identified in this study is similar to the novel variant recently described from Kuwait, thus indicating its second description in our region. ${ }^{5}$

We had previously reported CC1153-MSSA as nasal colonizer in health care workers at KKUH but this is the first identification of CC1153-MRSA in this facility. ${ }^{9}$ In our region, the two CC1153-MRSA isolates reported have been from Kuwait. ${ }^{5,20}$ Both isolates were $p v l^{+}$while one carried the SCCmec- $V$ and the other had SCCmec $\mathrm{I}+$ fus. Similar to these two, our isolate is $p v l^{+}$. Thus, all three CC1153 strains identified so far in the region show variability in their SCCmec types/ subtypes. It has been suggested that emergence of novel strains as reported for CC5-MRSA-IV, CC22-MRSA-IV and PVL-positive CC30-MRSA-IV might be due to the independent 
acquisition of SCCmec types/subtypes by the parental MSSA strains. ${ }^{6}$ This observation with CC1153-MRSA supports this premise for the emergence of novel MRSA strains.

CC22 is a widespread clonal group and six distinguishable strains based on SCCmec IV subtypes and virulence factors have been reported from this region. ${ }^{3}$ In this study, three of the previously reported CC22-MRS-IV strains were identified as well as a novel variant of CC22-MRSA-V characterized by carriage of the SCCmec $V / V T+f u s$ and $p v l^{+}$. Previously reported CC22-MRSA-[V+fus] from Saxony, Germany, were negative for $p v l$ gene. ${ }^{6}$ In Saudi Arabia, a single isolate of CC22-MRSA-V which did not carry the $p v l$ gene was reported as a nasal colonizer. ${ }^{21}$ The finding of this novel CC22-MRSA variant suggests the expanding repertoire of $\mathrm{CC} 22$ strains in this region.

$S$. argenteus is a newly identified staphylococcus species previously misidentified as $S$. aureus. ${ }^{22}$ The isolates identified in this study were phenotypically classified as $S$. aureus but found to be CC2250 S. argenteus on genotyping. This represents the second report of $S$. argenteus CC2250-MRSA-IV, WA MRSA-114 in Saudi Arabia having been previously identified from clinical infection in this health care facility. Indeed, $S$. argenteus has been shown to be of clinical relevance and isolates belonging to CC75, CC1233, CC2198, CC2250 and CC2854 have been described. ${ }^{22,23}$

\section{Conclusion}

Our findings demonstrate the emergence of novel variants of MRSA strains belonging to CC5, CC22, CC152 and CC361 as well as the first identification of other MRSA strains in Saudi Arabia. These findings are significant and indicative of an expanding repertoire of MRSA strains in our setting. This continued evolution of the MRSA genome arising from acquisition of resistance and virulence genes poses significant challenges for treatment and infection control. The role of fusidic acid misuse in driving this evolution underscores the need for increased monitoring of antibiotic use.

\section{Acknowledgment}

This study was partially funded by Strategic Research Grant no. 307191502153 from Alfaisal University, Riyadh, Saudi Arabia.

\section{Disclosure}

EM, AR, DG, RE, SM were employees at Alere Technologies GmbH/Abbott, Jena, Germany, at the time the study was carried out. The authors report no other conflicts of interest in this work.

\section{References}

1. Reddy PN, Srirama K, Dirisala VR. An update on clinical burden, diagnostic tools, and therapeutic options of Staphylococcus aureus. Infect Dis (Auckl). 2017;10:1179916117703999. doi:10.1177/11799 16117703999

2. Deurenberg RH, Stobberingh EE. The molecular evolution of hospital- and community-associated methicillin-resistant Staphylococcus aureus. Curr Mol Med. 2009;9(2):100-115.

3. Senok A, Somily A, Raji A, et al. Diversity of methicillin-resistant Staphylococcus aureus CC22-MRSA-IV from Saudi Arabia and the Gulf region. Int J Infect Dis. 2016;51:31-35. doi:10.1016/j.ijid.2016. 08.016

4. Deurenberg RH, Vink C, Kalenic S, Friedrich AW, Bruggeman CA, Stobberingh EE. The molecular evolution of methicillin-resistant Staphylococcus aureus. Clin Microbiol Infect. 2007;13(3):222-235. doi:10.1111/j.1469-0691.2006.01573.x

5. Boswihi SS, Udo EE, Monecke S, et al. Emerging variants of methicillin-resistant Staphylococcus aureus genotypes in Kuwait hospitals. PLoS One. 2018;13(4):e0195933. doi:10.1371/journal.pone.0195933

6. Monecke S, Jatzwauk L, Muller E, et al. Diversity of SCCmec elements in Staphylococcus aureus as observed in South-Eastern Germany. PLoS One. 2016;11(9):e0162654. doi:10.1371/journal. pone. 0162654

7. Bukharie HA. Increasing threat of community-acquired methicillinresistant Staphylococcus aureus. Am J Med Sci. 2010;340(5):378381. doi:10.1097/MAJ.0b013e3181e95fdc

8. Senok A, Ehricht R, Monecke S, Al-Saedan R, Somily A. Molecular characterization of methicillin-resistant Staphylococcus aureus in nosocomial infections in a tertiary-care facility: emergence of new clonal complexes in Saudi Arabia. New Microbes New Infect. 2016;14:13-18. doi:10.1016/j.nmni.2016.07.009

9. Senok A, Somily A, Raji M, et al. Genotyping of Staphylococcus aureus associated with nasal colonization among healthcare workers using DNA microarray. J Infect Dev Ctries. 2018;12(5):321-325. doi: $10.3855 /$ jidc. 10328

10. Monecke S, Coombs G, Shore AC, et al. A field guide to pandemic, epidemic and sporadic clones of methicillin-resistant Staphylococcus aureus. PLoS One. 2011;6(4):e17936. doi:10.1371/journal.pone.0017936

11. Ellington MJ, Reuter S, Harris SR, et al. Emergent and evolving antimicrobial resistance cassettes in community-associated fusidic acid and meticillin-resistant Staphylococcus aureus. Int $J$ Antimicrob Agents. 2015;45(5):477-484. doi:10.1016/j.ijantimicag. 2015.01.009

12. El-Mahdy TS, El-Ahmady M, Goering RV. Molecular characterization of methicillin-resistant Staphylococcus aureus isolated over a 2year period in a Qatari hospital from multinational patients. Clin Microbiol Infect. 2014;20(2):169-173. doi:10.1111/1469-0691.12240

13. Monecke S, Skakni L, Hasan R, et al. Characterisation of MRSA strains isolated from patients in a hospital in Riyadh, Kingdom of Saudi Arabia. BMC Microbiol. 2012;12:146. doi:10.1186/1471-2180$12-146$

14. Conceicao T, Tavares A, Miragaia M, Hyde K, Aires-de-Sousa M, de Lencastre $H$. Prevalence and clonality of methicillin-resistant Staphylococcus aureus (MRSA) in the Atlantic Azores islands: predominance of SCCmec types IV, V and VI. Eur J Clin Microbiol Infect Dis. 2010;29(5):543-550. doi:10.1007/s10096-010-0892-4

15. Dauwalder O, Lina G, Durand G, et al. Epidemiology of invasive methicillin-resistant Staphylococcus aureus clones collected in France in 2006 and 2007. J Clin Microbiol. 2008;46(10):34543458. doi:10.1128/JCM.01050-08 
16. Sa-Leao R, Santos Sanches I, Dias D, Peres I, Barros RM, de Lencastre H. Detection of an archaic clone of Staphylococcus aureus with low-level resistance to methicillin in a pediatric hospital in Portugal and in international samples: relics of a formerly widely disseminated strain? J Clin Microbiol. 1999;37(6):1913-1920.

17. Askarian F, van Sorge NM, Sangvik M, et al. A Staphylococcus aureus TIR domain protein virulence factor blocks TLR2-mediated NF-kappaB signaling. J Innate Immun . 2014;6(4):485-498. doi:10.1159/000357618

18. Durand G, Bes M, Meugnier H, et al. Detection of new methicillinresistant Staphylococcus aureus clones containing the toxic shock syndrome toxin 1 gene responsible for hospital- and communityacquired infections in France. J Clin Microbiol. 2006;44(3):847853. doi:10.1128/JCM.44.3.847-853.2006

19. Leroyer C, Lehours P, Tristan A, et al. Outbreak in newborns of methicillin-resistant Staphylococcus aureus related to the sequence type 5 Geraldine clone. Am J Infect Control. 2016;44(2):e9-e11. doi:10.1016/j.ajic.2015.09.020

20. Udo EE, Boswihi SS, Dimitrov TI, Noronha B, Mathew B. T. V. Characterization of a CC1153 PVL-producing community-acquired methicillin-resistant Staphylococcus aureus from a dog bite wound. J Infect Dev Ctries. 2017;11(6):513-516. doi:10.3855/jidc.8954
21. Abou Shady HM, Bakr AE, Hashad ME, Alzohairy MA. Staphylococcus aureus nasal carriage among outpatients attending primary health care centers: a comparative study of two cities in Saudi Arabia and Egypt. Braz J Infect Dis. 2015;19(1):68-76. doi:10.1016/j.bjid.2014.09.005

22. Hansen TA, Bartels MD, Hogh SV, et al. Whole genome sequencing of Danish Staphylococcus argenteus reveals a genetically diverse collection with clear separation from Staphylococcus aureus. Front Microbiol. 2017;8:1512. doi:10.3389/fmicb.2017.01512

23. Chantratita N, Wikraiphat C, Tandhavanant S, et al. Comparison of community-onset Staphylococcus argenteus and Staphylococcus aureus sepsis in Thailand: a prospective multicentre observational study. Clin Microbiol Infect. 2016;22(5):458 e411-458 e459. doi:10.1016/j. cmi.2016.01.008

\section{Publish your work in this journal}

Infection and Drug Resistance is an international, peer-reviewed openaccess journal that focuses on the optimal treatment of infection (bacterial, fungal and viral) and the development and institution of preventive strategies to minimize the development and spread of resistance. The journal is specifically concerned with the epidemiology of antibiotic resistance and the mechanisms of resistance development and diffusion in both hospitals and the community. The manuscript management system is completely online and includes a very quick and fair peerreview system, which is all easy to use. Visit http://www.dovepress.com/ testimonials.php to read real quotes from published authors. 